\title{
Agreeing criteria for audit of the management of induced abortion: an approach by national
}

\section{consensus survey}

\author{
Gillian C Penney, Anna Glasier, Allan Templeton
}

\begin{abstract}
Objective-To obtain a national consensus view of suggested criteria for good quality care in induced abortion to serve as a basis for standards for audit to assess current clinical practice.

Design-Postal, questionnaire survey assessing consensus agreement with criteria identified from a literature review and refined by an invited panel of four gynaecologists and the gynaecology audit project in Scotland (GAPS) committee. Setting-Scotland.
\end{abstract}

Subjects-All 132 practising consultant gynaecologists.

Main measures-Overall level of agreement with each of 20 suggested audit criteria.

Results-121 completed questionnaires were received (response rate $92 \%$ ), of which 119 were returned in time for analysis; 107 came from consultants who practised abortion routinely and were included in the analysis. Nineteen of 20 suggested criteria were validated by an overall balance of agreement. The most strongly supported criterion (agreement score +93) was for ascertaining rhesus status of the woman and prophylaxis after abortion, if indicated. The only criterion to elicit a negative agreement score $(-27)$ was that dilatation and evacuation is the best method of abortion at 12-15 weeks' gestation. The ranked and prioritised criteria resulting from this exercise are being used within a national audit project.

Conclusions-A postal questionnaire survey among interested clinicians resulted in a good response rate and enabled the audit criteria to be validated and ranked more objectively and among more clinicians, than would have been possible by group discussion.

(Quality in Health Care 1993;2:167-169)

\section{Introduction}

Criterion based audit has been described as offering a valuable and realistic method of audit based on review of medical records. ${ }^{1-3}$ In this approach key elements of clinical management (audit criteria) are agreed by participating clinicians. Case notes can then be reviewed by non-medical audit assistants who extract selected data relating to the agreed criteria. Shaw suggested that around 15 such criteria can be addressed in a single audit. ${ }^{1}$

The practical difficulties of establishing audit criteria acceptable to all participating clinicians are acknowledged, ${ }^{2}$ and it has been suggested that criteria should be based on the findings of a literature review combined with discussion by the audit group. Discussion by all participating clinicians is clearly impractical for large scale audit projects undertaken regionally or nationally. This paper describes an approach to agreeing audit criteria, incorporating a postal questionnaire survey of all involved clinicians, which has been developed and used successfully in a national audit project.

The gynaecology audit project in Scotland (GAPS) was initiated by the Scottish Executive Committee of the Royal College of Obstetricians and Gynaecologists with the aim of auditing three topics (induced abortion, endometriosis, and carcinoma of the vulva) nationally. The audit of each topic is seen as an end in itself, but, in addition, the project as a whole is seen as an opportunity to develop approaches to the methodology of audit which can be applied subsequently to further topics.

The approach to establishing audit criteria which has been developed within this project is described with reference to the first topic, induced abortion.

\section{Methods}

A review of contemporary medical literature relating to the management of induced abortion provided the basis for a provisional list of statements, or criteria, which were seen as summarising essential elements of good quality care. The criteria covered four, previously agreed broad areas of abortion care: organisation of the service, investigations before abortion, methods of abortion, and care after abortion.

For example, Criterion 1 - Women requesting induced abortion should be offered an appointment with a gynaecologist within five days of referral.

This criterion was taken from the Birth Control Trust model service specification ${ }^{4}$ which provided the basis for several of the suggested criteria under the "organisation of the service" heading. The provisional list of criteria was then modified and refined by means of discussions with two separate groups of clinicians: an invited panel of four 
gynaecologists (two with a special interest in abortion care and two generalists) and also the GAPS steering committee.

A questionnaire was then designed to assess "level of agreement" with each of 20 criteria in the final list. Respondents were asked: "The following list of statements relating to the management of induced abortion has been drawn up following a literature review and discussion with a panel of clinicians. We would like you to indicate your level of agreement with each statement as representing an important criterion for good quality care on a 5 point scale graded as follows: 1 strongly agree, 2 agree, 3 neither agree nor disagree, 4 disagree, or 5 strongly disagree."

In September 1992 the questionnaire was sent to all 132 consultant gynaecologists practising in Scotland. The mailing list was based on names and addresses provided by the college and updated by means of telephone inquiry to all 26 gynaecology units in Scotland. A second copy of the questionnaire, with a letter of reminder, was sent to those consultants who had not responded within two weeks. Data from the questionnaires were entered into a purpose designed database using Paradox (Borland) software on an IBM compatible personal computer.

Each criterion was allocated an "agreement score" in order to convey the overall balance of agreement with each criterion among consultants. In allocating the agreement scores each response of "strongly agree" scored +2, "agree" +1 , "neutral" 0 , "disagree" -1 , and "strongly disagree" -2 . The scores for each criterion were then summed and expressed as a percentage of the maximum possible score had all consultants strongly agreed (that is, of 204) to give the final "agreement score". Thus, any positive score indicates a balance of agreement, +100 is the maximum possible score and -100 is the minimum possible score.

\section{Results}

As a result of the two mailings, 121 completed questionnaires were eventually received (a response rate of $92 \%), 119$ in time for analysis. Of the 119 respondents, 12 indicated that they never accepted abortion referrals and answered no further questions. Thus, the opinions on abortion care of those 107 respondents who manage induced abortion in the course of their routine practice were used to validate the audit criteria.

The table shows all 20 criteria, in summary form, ranked according to the agreement score allocated to each. The agreement scores represent an attempt to indicate the balance of agreement with each criterion, giving additional weighting to responses of strongly

Suggested criteria for good quality abortion care ranked by level of agreement among 107 Scottish consultants

\begin{tabular}{|c|c|c|c|}
\hline Ranking & $\begin{array}{l}\text { Agreement score } \\
\text { (Possible score } \\
+100 \text { to }-100)\end{array}$ & $\begin{array}{l}\text { Consultants who } \\
\text { agreed or } \\
\text { strongly agreed } \\
\text { (\%) }\end{array}$ & Abbreviated criterion \\
\hline 1 & +93 & 100 & Rhesus status should be determined before abortion \\
\hline 2 & +69 & 95 & Cervical predilatation indicated for selected patients \\
\hline 3 & +61 & 90 & $\begin{array}{l}\text { Surgical abortion at gestation }>11 \text { weeks requires an } \\
\text { experienced operator (beyond member of Royal } \\
\text { College of Obstetricians and Gynaecologists or } \\
\text { equivalent) }\end{array}$ \\
\hline 4 & +60 & 88 & $\begin{array}{l}\text { If indicated, oral contraception should begin immediately } \\
\text { after abortion }\end{array}$ \\
\hline 5 & +59 & 87 & Surgical abortion should be managed on a day case basis \\
\hline 6 & +58 & 82 & $\begin{array}{l}\text { Contraceptive advice and supplies should be provided } \\
\text { after abortion }\end{array}$ \\
\hline 7 & +56 & 83 & $\begin{array}{l}\text { Advice on "emergency contraception" should be provided } \\
\text { after abortion }\end{array}$ \\
\hline 8 & +51 & 79 & $\begin{array}{l}\text { The "appointment to abortion" interval should be } \\
\leq 7 \text { days }\end{array}$ \\
\hline 9 & +50 & 81 & The "referral to appointment" interval should be $\leq 5$ days \\
\hline 10 & +44 & 68 & $\begin{array}{l}\text { There should be a policy for treating potential genital } \\
\text { tract infection }\end{array}$ \\
\hline 11 & +43 & 80 & Routine ultrasonography is unnecessary before abortion \\
\hline 12 & +41 & 78 & $\begin{array}{l}\text { "Induction to abortion" interval should be }<24 \text { hours at } \\
>15 \text { weeks' gestation }\end{array}$ \\
\hline 13 & +40 & 72 & $\begin{array}{l}\text { Abortion patients should begin cervical screening } \\
\text { regardless of age }\end{array}$ \\
\hline 14 & +39 & 74 & $\begin{array}{l}\text { Surgical evacuation should not be routine after medical } \\
\text { abortion }\end{array}$ \\
\hline 15 & +34 & 63 & $\begin{array}{l}\text { Women at }<9 \text { weeks' gestation should have a choice of } \\
\text { surgical/medical abortion }\end{array}$ \\
\hline 16 & +25 & 40 & $\begin{array}{l}\text { Mifepristone reduces the induction to abortion interval in } \\
\text { the } 2 \text { nd trimester }\end{array}$ \\
\hline 17 & +23 & 59 & $\begin{array}{l}\text { All abortion patients should be offered a follow up } \\
\text { appointment }\end{array}$ \\
\hline 18 & +14 & 41 & $\begin{array}{l}\text { Surgical abortion should be avoided at gestations }<6 \\
\text { weeks }\end{array}$ \\
\hline 19 & +6 & 33 & $\begin{array}{l}\text { The follow up appointment should be within } 14 \text { days of } \\
\text { the abortion }\end{array}$ \\
\hline 20 & -27 & 19 & $\begin{array}{l}\text { At gestations of } 12-15 \text { weeks dilatation and evacuation is } \\
\text { the method of choice }\end{array}$ \\
\hline
\end{tabular}


agree or disagree. The percentage of respondents who agreed or strongly agreed with each criterion is also shown. Nineteen of the 20 suggested criteria gained positive agreement scores, indicating an overall balance of agreement. However, the ranked criteria may be viewed as forming a range in terms of their agreement scores and thus in terms of the importance that can be attached to them as a basis for acceptable audit standards against which current practice may be judged and towards which clinicians might aspire.

The most strongly supported criterion, with an agreement score of 93 out of a theoretical maximum of 100 was: The woman's rhesus status should be ascertained and $R h$ prophylaxis given after the abortion if indicated. All respondents agreed with this criterion, almost $85 \%$ strongly agreed. This fundamental component of abortion care is clearly acceptable to all as a target to be met in providing an abortion service.

Among the least strongly supported of those criteria gaining positive scores were those relating to follow up after abortion. $A$ follow up appointment, either at the hospital, or with the referring doctor, should be given to every patient was ranked only 17 out of 20 , and less than $60 \%$ of respondents agreed with it. The follow up appointment should be within 14 days of the abortion was ranked 19/20; only a third of respondents actively agreed with it, most felt "neutral". Thus, although the Birth Control Trust and also the Scottish Home and Health Department's Study Group on the management of gynaecological services emphasise that the abortion service should encompass such aftercare, ${ }^{45}$ these criteria were not given high priority by Scottish consultants.

Only one of the suggested criteria gained a negative agreement score (-27): At gestations of 12-15 weeks surgical abortion (dilatation and evacuation) is the method of choice. This criterion is well supported by results from large series of patients managed in the United States $^{67}$ but is clearly not acceptable in Scotland at present as a criterion for good quality care.

\section{Discussion}

The results of the national survey have enabled us to produce a list of criteria, ranked according to their relative importance to Scottish gynaecologists. It seems reasonable to regard the 19 statements for which there was an overall balance of agreement as valid criteria for audit against which to measure current practice. This process is currently underway in the form of a prospective, case note review audit of induced abortion in 10 representative hospitals throughout Scotland.

The ranking of the criteria according to their relative importance will enable those aspects of care which fail to measure up to the criteria to be similarly ranked. This will be helpful in deciding which aspects of care warrant change and in prioritising such changes for the allocation of resources. For example, if it were found in the course of prospective audit that the rhesus status of abortion patients was not being routinely measured, then participating clinicians, who judged this to be of fundamental importance would be expected to give high priority to implementing change in this aspect of care whereas this would not be so if it were found that abortion patients were not routinely being given follow up appointments within 14 days of their procedure.

For aspects of care (such as follow up arrangements) in which the views of "specialists" in abortion care ${ }^{458}$ differ from those of the generality of consultants, the low ranking of relevant criteria serves to highlight appropriate topics for educational initiatives. For such aspects of care opinion must be changed before there can be hope of changing practice. In this study the views of consultant gynaecologists have been used to estimate the relative importance of different aspects of abortion care. Consultants seem to rank "technical" aspects of care more highly than the "supportive" aspects such as follow up. Other interested groups such as nursing staff and consumers might have ranked the different elements of care differently.

This approach to establishing audit criteria could be applied to other topics by surveying clinicians on a geographical basis, as was done here, or by surveying the membership of specialist professional groups and societies with regard to more specialised topics.

The survey described was undertaken to establish criteria for audit rather than to develop formal clinical practice guidelines. However, a recent working group document from the Scottish Home and Health Department has highlighted the close relation between audit and development of guidelines (Clinical Resource and Audit Group, 1992, unpublished), and the consensus approach used here could appropriately be applied to the validation of guidelines and local protocols.

In addition to the authors, the following gynaecologists served on the two discussion panels: Philip Myerscough, Sheil Lawson, Richard Henshaw, Marion Hall, Henry Kitchener, Ian Duncan. Ian Russell and Barbara Thompson gave methodological advice; Elaine Stirton typed the questionnaire and manuscript. The GAPS project is funded by a grant from the Clinical Resource and Audit Group of the Scotrish Office Home and Health Department. We thank the consultant gynaecologists who responded to the questionnaire for their cooperation.

1 Shaw CD. Criterion based audit. In: Smith R, ed. Audit in action. London: BMJ, 1992:122-8.

2 Moving to audit. Dundee: Ninewells Hospital and Medica School, 1992

3 Ruta D, Wilson B. A handbook of medical audit for hospital doctors. Aberdeen: Grampian Health Board, 1992.

4 Birth Control Trust. Model service specification: services for women requesting abortion. London: Birth Control Trust, 1991:1-10.

5 Scottish Home and Health Department, Scottish Health Service Advisory Council. Report of the study group on the management of gynaecological services in Scotland. London: HMSO, 1991.

6 Grimes DA, Schulz KF, Cates W, Tyler Jr CW. Midtrimester abortion by dilatation and evacuation: a safe and practic

7 Peterson WF, Berry FN, Grace MR, Gulbranson CL. Second-trimester abortion by dilatation and evacuation: an analysis of 11,747 cases. Obstet Gynecol 1983;62 185-90.

8 Glasier A. The organisation of abortion services. Current Obstetrics and Gynaecology (in press). 